\title{
Wedge resection and segmentectomy in patients with stage I non-small cell lung carcinoma
}

\author{
Konstantinos Reveliotis, ${ }^{1}$ George Kalavrouziotis, ${ }^{2}$ Konstantinos Skevis, ${ }^{1}$ Andriani Charpidou, ${ }^{3}$ \\ Rodoula Trigidou, ${ }^{3}$ Kostas Syrigos ${ }^{3}$ \\ ${ }^{1}$ Thoracic Department, General Hospital of Rhodes, Rhodes; ${ }^{2}$ Department of Cardiothoracic \\ Surgery, Children's Hospital Aghia Sophia, Athens; ${ }^{3}$ Oncology Unit GPP, Sotiria General \\ Hospital, Athens Medical School, Greece
}

\begin{abstract}
The use of sublobar resections as definitive management in stage I non-small cell lung carcinoma is a controversial topic in the medical community. We intend to report the latest developments and trends in relative indications for each of the above-mentioned surgical approaches for the treatment of stage I non-small cell lung carcinoma as well as the results of studies regarding local recurrence, disease-free survival and five-year survival rates. We reviewed 45 prospective and retrospective studies conducted over the last 25 years listed in the Pubmed and Scopus electronic databases. Trials were identified through bibliographies and a manual search in journals. Authors, citations, objectives and results were extracted. No meta-analysis was performed. Validation of results was discussed. Segmentectomies are superior to wedge resections in terms of local recurrences and cancer-related mortality rates. Sublobar resections are superior to lobectomy in preserving the pulmonary parenchyma. High-risk patients should undergo segmentectomy, whereas lobectomies are superior to segmentectomies only for tumors $>2 \mathrm{~cm}$ (T2bN0M0) in terms of disease-free and overall 5-year survival. In most studies no significant differences were found in tumors $<2 \mathrm{~cm}$. Disease-free surgical margins are crucial to prevent local recurrences. Systematic lymphadenectomy is mandatory regardless of the type of resection used. In sublobar resections with less thorough
\end{abstract}

Correspondence: Kostas Syrigos, Oncology Unit GPP, Sotiria General Hospital, Athens Medical School, 152 Mesogeion, Athens, 115 27, Greece. Tel.: +302107700220 - Fax: +302107781035 .

E-mail: ksyrigos@med.uoa.gr

Conflict of interests: the authors declare no conflict of interests.

Key words: non-small-cell lung carcinoma, thoracic surgery.

Received for publication: 16 September 2013.

Revision received: 27 February 2014.

Accepted for publication: 6 March 2014.

This work is licensed under a Creative Commons Attribution NonCommercial 3.0 License (CC BY-NC 3.0).

(C) Copyright K. Reveliotis et al., 2014

Licensee PAGEPress, Italy

Oncology Reviews 2014; 8:234

doi:10.4081/oncol.2014.234 nodal dissections, adjuvant radiotherapy can be used. This approach is preferable in case of prior resection. In pure bronchoalveolar carcinoma, segmentectomy is recommended. Sublobar resections are associated with a shorter hospital stay. The selection of the type of resection in TlaN0M0 tumors should depend on characteristic of the patient and the tumor. Patient age, cardiopulmonary reserve and tumor size are the most important factors to be considered. However further prospective randomized trials are needed to investigate the efficacy of minimal resections in early lung cancer patients.

\section{Introduction}

In recent years there has been an ongoing controversy in the international medical community regarding the surgical indications for wedge resection and segmentectomy in patients with stage I non-small cell lung cancer (NSCLC).

Traditionally the most appropriate surgical approach in these patients, regardless of the location or size of the tumor, has always been lobectomy with a complete lymph node dissection. ${ }^{1}$ Two other minor surgical interventions, i.e. wedge resection and segmentectomy, are also considered treatments of choice in patients with a compromised cardiorespiratory reserve. This approach has been traditionally based on the study conducted by the 1995 Lung Cancer Study Group, which came to the conclusion that these two types of sublobar resection compared to lobectomy were statistically associated with a significantly greater incidence of local recurrence. ${ }^{2}$ At the same time, no statistically significant difference was identified in overall survival or improvement in lung function one year after surgery. The only statistically significant difference reported was in the reduction of postoperative forced expiratory volume in the $1^{\text {st }}$ second (FEV1), but not of forced vital capacity (FVC), in favor of smaller resections. This is the only randomized trial ever conducted on this topic to date.

In the last decade, though, several important prospective and retrospective studies have been performed, mainly in Japan, and led to different conclusions. ${ }^{3,4}$ Computed tomography (CT) screening strategies for lung cancer detection have been implemented in this country since the 1980's and have led to the diagnosis and surgical treatment of many much smaller peripheral tumors ( $>1 \mathrm{~cm}$ in diameter) than in the past. The reasonable question raised by Japanese colleagues was whether lobar resection is appropriate for such small peripheral tumors. The conclusion of this study group was that, for specific stage I (cTlaN0M0) tumors $<2 \mathrm{~cm}$, there is no statistically significant difference between lobectomy and extended segmentectomy in terms of local recurrence and lung cancer-related 5-year survival rates. ${ }^{3,4}$ 
The objectives of this literature review are to describe the evolution of indications for wedge resection and segmentectomy versus lobectomy in non-small cell lung cancer within the international community and to gather the results achieved with each technique in terms of local recurrence rates, disease-free survival time and overall survival, as reported in the conclusions of the most important studies conducted in this field over the last thirty years.

\section{Methods of research}

We searched the Medline database using the OVID interface [Lobectomy.mp OR Lobar resection.mp] AND [Stage I non-small cell lung cancer.mp OR Stage I non-small cell carcinoma.mp] AND [Sublobar resection.mp OR limited resection.mp OR Segmentectomy.mp OR Wedge resection.mp] until May 2013. More specifically, we searched for prospective or retrospective studies comparing lobectomies with sublobar resections (segmentectomies, wedge resections) in patients with stage I NSCLC focusing on survival and recurrence rates as well as nononcological advantages associated with each surgical approach. Relevant articles and appropriate references extracted from these articles were used to make this review. Only articles written in English and with access to full-text manuscripts were included. Papers which did not meet all the above criteria were excluded.

\section{Results}

\section{Survival and recurrence}

We found 24 papers comparing sublobar resections with lobectomies in terms of overall survival and recurrence rates for stage I non-small cell lung cancer (NSCLC). These studies are reported in Table 1, ${ }^{2,5-27}$ Fifteen studies showed an equivalence between minor resections and lobectomies, $5,7,10$ $15,17-20,22,25,27$ while 9 studies demonstrated the superiority of lobectomies versus wedge resections and segmentectomies. ${ }^{2,6,8,9,16,21,23,24,26}$ Among these the only prospective randomized trial performed so far is the one conducted by the 1995 Lung Cancer Study Group. ${ }^{2}$

The first reference to segmentectomy was made in 1939 by Churchill and Belsey for the treatment of patients with bronchiectasis. ${ }^{28}$ Many years later, in 1973, Jensik and colleagues performed the first segmentectomy in a patient with lung carcinoma. ${ }^{29}$

One of the first studies showing the superiority of lobectomy over minor resections was the retrospective study by Warren and Faber involving 169 patients with stage I non-small cell lung carcinoma who underwent either segmentectomy (66 patients) or lobectomy (103 patients). This study demonstrated similar overall survival rates at 5 years between the 2 groups, but statistically significant different rates of local recurrences $(22.7 \%$ vs $4.9 \%, \mathrm{P}<0.05)$. It should be noted that all patients were able to tolerate lobectomy. ${ }^{8}$ The Lung Cancer Study Group led by Ginsberg et al. $^{2}$ followed in 1995, demonstrating a 3 -fold increase in local relapses among patients who underwent sublobar resections versus lobectomies ( $\mathrm{P}=0.02$ for recurrences in total, $\mathrm{P}=0.008$ for locoregional recurrences). No statistically significant difference was found in terms of overall survival between the two groups. In 1997, Landreneau et al. ${ }^{9}$ compared the results of wedge resection (be it a video-assisted thoracoscopic or open surgery) versus lobectomy in 102 and 117 patients with cT1NO NSCLC respectively and found a trend towards higher local recurrence rates in the wedge resection group ( $19 \%$ vs $9 \%, \mathrm{P}=0.07)$ and a significant difference in overall survival between the sub-group of open wedge resection and the group of lobectomy (but no significant difference between the total wedge resection group and the lobectomy group).

In 2002 Miller et al. in another retrospective study ${ }^{6}$ on stage I NSCLC
(cTINOM0) patients and tumor size $<1 \mathrm{~cm}$ demonstrated statistically significant differences in terms of overall survival ( $71 \%$ vs $33 \%, \mathrm{P}=0.03)$ and cancer-specific 5 -year survival ( $99 \%$ vs $47 \%, \mathrm{P}=0.07)$ in favor of lobectomy. Okada retrospectively studied 1221 stage I NSCLC patients and found significant differences in 5-year survival rates only in tumors $>31 \mathrm{~mm}(\mathrm{P}=0.0492)$, but not in smaller tumors. ${ }^{16}$ Nakamura et al. in 2011 showed lower 5-year survival rates in wedge resection (but not in segmentectomy) compared to lobectomy (HR for WR compared to lobectomy: 4.30), ${ }^{21}$ while Wolf et al. observed that lobectomy was associated with longer overall survival $(\mathrm{P}=0.0027)$ and longer recurrence-free survival $(\mathrm{P}=0.0496) .{ }^{23}$ Nevertheless, when lymph nodes were sampled with sublobar resection, the distributions of the local recurrence rate and the recurrence-free survival were similar to those of lobectomy. Lastly Whitson et al. studied 14,473 cases using the Surveillance Epidemiology and End Results database (1998-2007) and concluded that lobectomy offered a superior unadjusted overall $(\mathrm{P}<0.0001)$ and cancer-specific $(\mathrm{P}=0.0053)$ 5-year survival compared with segmentectomy, even after adjusting for patient factors and tumor characteristics. ${ }^{24}$

On the other hand, Errett et al. in 1985 were the first to show an equivalence between wedge resection and lobectomy in terms of six-year survival rates. ${ }^{7}$ An increasing number of studies have followed, especially in the last decade, demonstrating no significant differences in overall survival and recurrence rates between either wedge resection or segmentectomy or both and lobectomy for stage I NSCLC. This evidence was much stronger in tumors with a diameter $\leq 2 \mathrm{~cm} \cdot{ }^{5,11,12,16}$ Among these studies, the only prospective, yet non-randomized trial was conducted by Okada et al. in 2006 on 565 patients (230 underwent segmentectomy, 32 wedge resection and 303 lobectomy). No statistically significant difference was found in terms of 5 -year survival and recurrence rates, ${ }^{10,13-15}$ but also more recent retrospective studies ${ }^{20,21}$ came to similar conclusions.

\section{Age and tumor size}

We did not establish a clear and strong correlation between the age of patients and the type of operation selected. Four studies found a trend in the older age of patients undergoing lobectomy, ${ }^{12,15,30,31}$ while 2 studies showed that patients submitted to sublobar resection tended to be older ${ }^{13,21}$ and 5 studies demonstrated that patients undergoing limited resection were significantly older. ${ }^{7,9,17,23,24}$ Three of these last set of 5 studies demonstrated the superiority of lobectomy over limited resection, ${ }^{9,23,24}$ while the other two studies showed an equivalence between the two types of surgery. 7,17

At to the tumor size, 5 studies found larger tumors in patients submitted to lobectomy, ${ }^{5,9,12,14,16}$ while 3 more studies showed that the difference in tumor size was statistically significant. ${ }^{19,31,24}$

\section{Non-oncological advantages of sublobar resections}

In 2004, Keenan et al. compared the results of lobectomies versus segmentectomies in 201 patients and found that at 1-year follow-up patients undergoing lobectomies showed a statistically significant decrease in FEV1 (from 75.1\% to 66.7\%), FVC (from 85.5\% to 81.1\%), maximal voluntary ventilation (from $72.8 \%$ to $65.2 \%$ ) and carbon monoxide diffusing capacity (DLC0) (from 79.3\% to 69.6\%). Conversely, in the second group of patients, there was a statistically significant reduction only of DLCO. Therefore the authors concluded that in the sublobar resection group a better lung function was preserved, despite the overall worse preoperative respiratory status. ${ }^{13}$ In 2005 , the study of Harada et al. achieved similar results. ${ }^{31}$ Later, in 2006, Okada et al. demonstrated that the lung function loss rate is directly related to the number of segments resected, as reflected by the increased rate of postoperative reduction of FVC and FEV1 in the lobectomy group. ${ }^{15}$ None of the above studies showed any significant difference between segmentectomies and lobectomies in terms of overall survival.

However a study by Korst et al. showed that lobectomy gave better results in a group of patients with emphysema in terms of preservation 
of lung function compared to smaller resections. ${ }^{32}$ This is consistent with the rationale of combined surgical oncological procedures and lung volume reduction surgery.

\section{Sublobar resections and adjuvant radiotherapy}

In 2003 , in a retrospective study, Santos et al. found statistically significant differences in local recurrence rates in 2 groups of patients with Stage I NSCLC that were submitted to either sublobar resection or sublobar resection with intraoperative Il 25 brachytherapy with mesh $(18.6 \% \mathrm{vs}$ $2 \%, \mathrm{P}=0.0001) .{ }^{33}$ Similarly, in 2005 , in a retrospective multicenter study on 291 patients (167 treated with lobectomy and 124 with segmentectomy or wedge resection with or without brachytherapy) Fernando et al. observed that local recurrence rates in the second group fell from $17.2 \%$ to $3.3 \%$, revealing a statistically significant difference, if concomitant brachytherapy is used. ${ }^{34}$ In addition, in a retrospective study on patients undergoing wedge resection or segmentectomy with Il25 brachytherapy with mesh, Lee et al. demonstrated a local recurrence rate which was lower than normal (6.1\%), but higher than in the previous two studies, probably because of the larger number of wedge resections. ${ }^{35}$ In a retrospective analysis, Birdas et al. compared the outcomes of smaller resections with concomitant brachytherapy and lobectomies in 167 stage IB patients (41 in the first group and 126 in the second) and found no statistically significant difference in local recurrence (4.8\% vs $3.2 \%)$, disease-free survival and overall survival rates. ${ }^{36}$ Finally, we are looking forward to the announcement of the results of the ACOSOG Z4032 clinical trial of the American College of Surgeons Oncology Group, which are expected to offer conclusive clarifications as to the actual role of brachytherapy in the reduction of locoregional recurrences.

\section{Discussion}

The selection of the surgical approach in stage I NSCLC patients is still a source of major controversy. The basic argument in favor of sublobar resections is that most studies showing the superiority of lobectomies are not properly randomized and do not consider factors affecting survival, such as tumor size, differences between wedge resection and segmentectomy and type of lymph node dissection. Furthermore, the follow-up of the patients is often incomplete. Therefore, for example, with regard to the conclusions from the study by the Lung Cancer Study Group, which was also the most influential, given it is the only randomized trial conducted so far, but also because it was written by this group of surgeons in particular, the supporters of sublobar resections underline that $30 \%$ of sublobar resections were wedge resections and not segmentectomies, leading to differences in results, as previously mentioned. In many studies either no distinction is made between wedge resections and segmentectomies or the exact number of each type of surgery is not reported, thus resulting in misleading conclusions in favor of lobectomies. Furthermore, in this study, the size of tumors is up to $3 \mathrm{~cm}$, thus creating once again a bias in favor of lobectomies, since the subsequent studies by the Japanese colleagues have clearly demonstrated that only tumors up to $2 \mathrm{~cm}$ are an indication for segmentectomy.

Bearing this critical issue in mind, when the Japanese researchers designed their more recent studies, they set stricter admission criteria, whereby: i) enrolled patients should have exclusively stage cTIaNOMO tumors $<2 \mathrm{~cm}$; ii) the only surgical procedure admitted is extended segmentectomy with complete lymph node dissection in which the affected lung segment and a small part of the adjacent segment are completely removed with the appropriate technique, while all local NIa, NIb and selected mediastinal (N2) lymph nodes are dissected; iii) intraoperative staging should always be considered. When the clinical picture changes, as a result of intrapulmonary metastases or infiltrated lymph nodes, surgical treatment should also be reconsidered and changed to lobectomy with lymph node dissection. In relation to the last two criteria the differences in locoregional recurrence rates in sublobar resections between the studies of the Japanese group and the studies conducted in Western countries are partly attributable to the increased or unknown proportion of wedge resections and also to the lack of strict and clear indications of the tumor size in the latter set of studies. ${ }^{15}$

One of the advantages of more limited surgical resections than lobectomy is the anatomical preservation of more functional segments of the lung. This has a two-fold positive effect, since on the one hand it is associated with a better preservation of lung function, while, on the other, in case of recurrence or a second primary lung carcinoma, it increases the likelihood of a better tolerated reoperation. Limited resections are now considered to be superior to lobectomies as far as the preservation of lung function is concerned. Since in limited resections a smaller percentage of healthy lung parenchyma is lost, this statement, although seemingly reasonable, has only recently been accepted by the scientific community. Again, the first studies on this topic, such as that of the Lung Cancer Study Group in 1995, did not report statistically significant differences between the two groups in the reduction of postoperative lung function at first year follow-up, unlike what was demonstrated in subsequent studies. ${ }^{13-15,31}$

In an attempt to reduce local recurrence rates after sublobar resection, techniques of adjuvant radiotherapy, such as intraoperative brachytherapy, have been introduced in the clinical practice. In brachytherapy, sutures with seeds $I^{125}$ with or without a simultaneous mesh graft are placed over the stapler line. One of the advantages of this method is the focused irradiation only of the tissue area around the resection margins, thus requiring lower total doses of radiation. Furthermore, it increases the compliance of patients to treatment, since they are not obliged to return to the hospital after discharge.

Lastly, also the histological profile of the tumor affects the outcome and the treatment selection. For example, in the case of a bronchoalveolar carcinoma without active fibroblast proliferation and vascular invasion, wedge resection is considered an appropriate option, ${ }^{37,38}$ due to the relative benign nature of this specific tumor. In this case the CT scans shows typical ground glass opacities without any other accompanying abnormalities.

\section{Conclusions}

Sublobar surgical resections have an absolute indication for highrisk surgical patients who cannot tolerate lobectomy due to a compromised cardiorespiratory reserve. Segmentectomies have proved to be superior to wedge resections in terms of oncological results in several studies. Wedge resection is indicated in bronchoalveolar carcinoma with no evidence of active fibroblast proliferation. Recent studies have demonstrated that extended segmentectomy has comparable oncological results in terms of 5-year survival and local recurrence rates with lobectomy for stage IA patients with tumors smaller than $2 \mathrm{~cm} .^{3,21}$ The innovation in this conclusion is that the Japanese researchers extend the indications for a more limited intervention than lobectomy to this subgroup of patients with low surgical risk, who had been previously considered candidates for lobectomy only. A new prospective randomized study is now required to shed more light on this controversy. In America, this study is already in progress with the name of Cancer and Leukemia Group B 140503 and is expected to be published shortly. Sublobar resections are associated with a better preservation of the respiratory function compared to lobectomies. New methods based on adjuvant radiotherapy are applied in patients undergoing wedge resection or segmentectomy in an effort to reduce local recurrence rates. Final results are expected from a large randomized prospective study (ACOSOG Z4032), which has not yet been completed. 

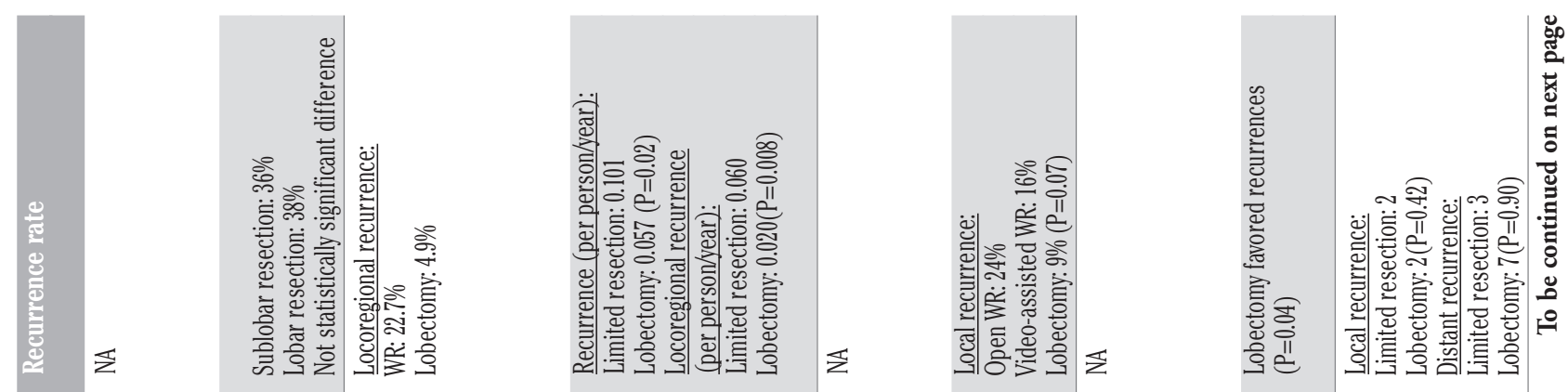

范产言言

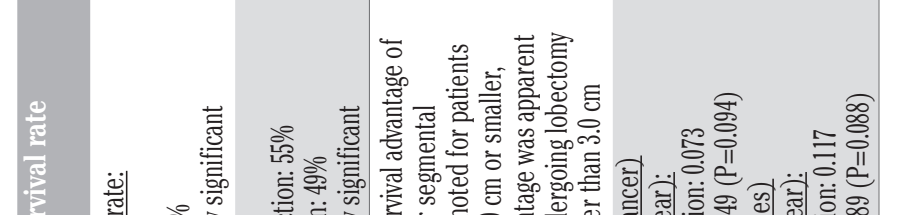

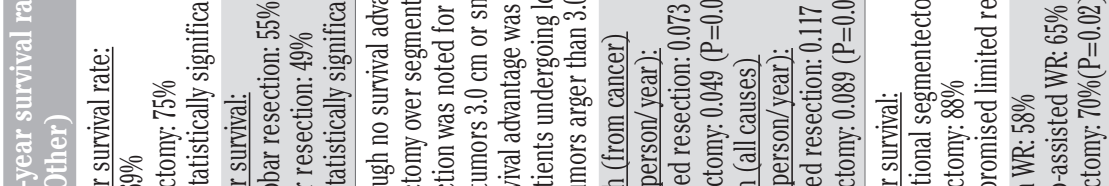

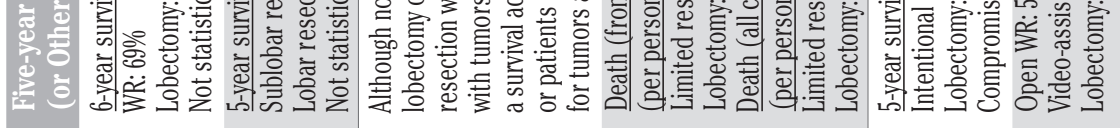

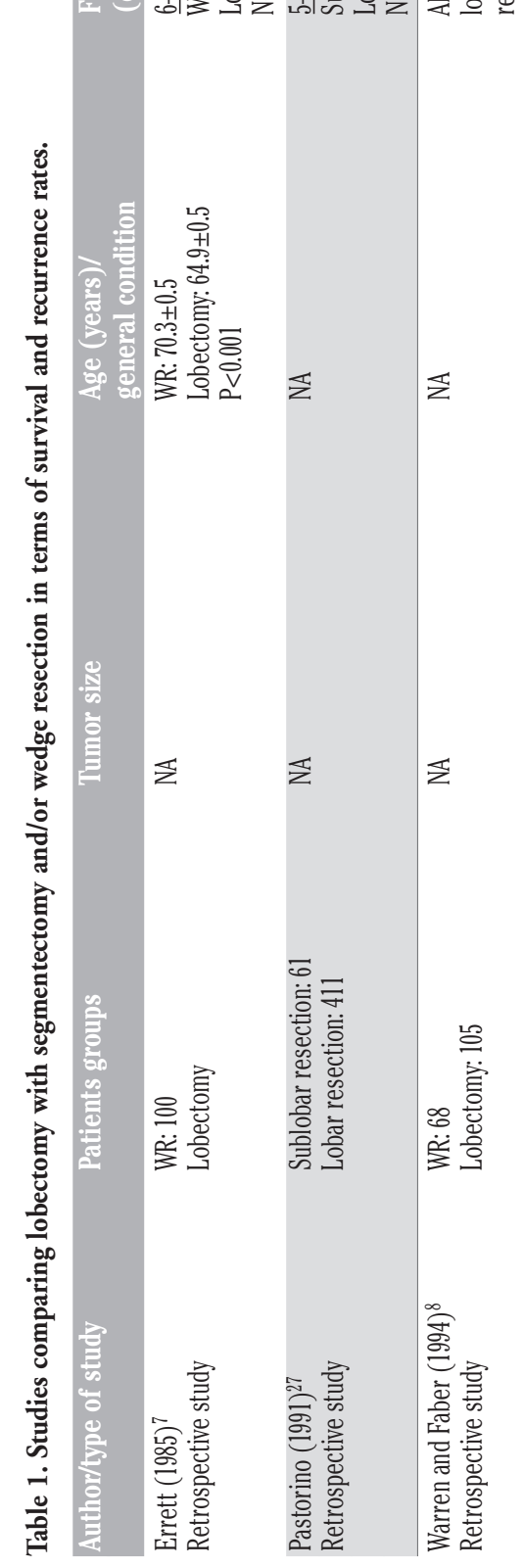

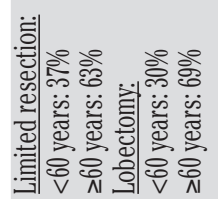
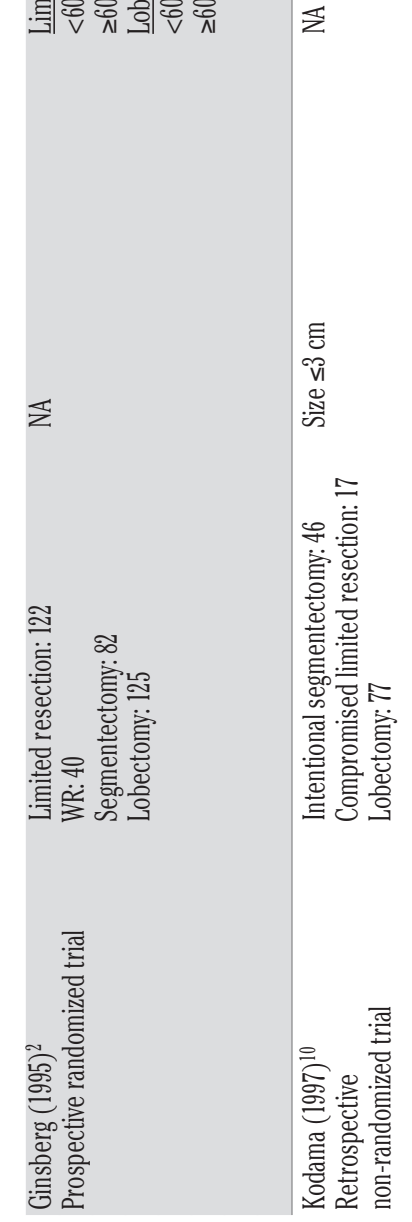

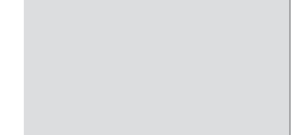




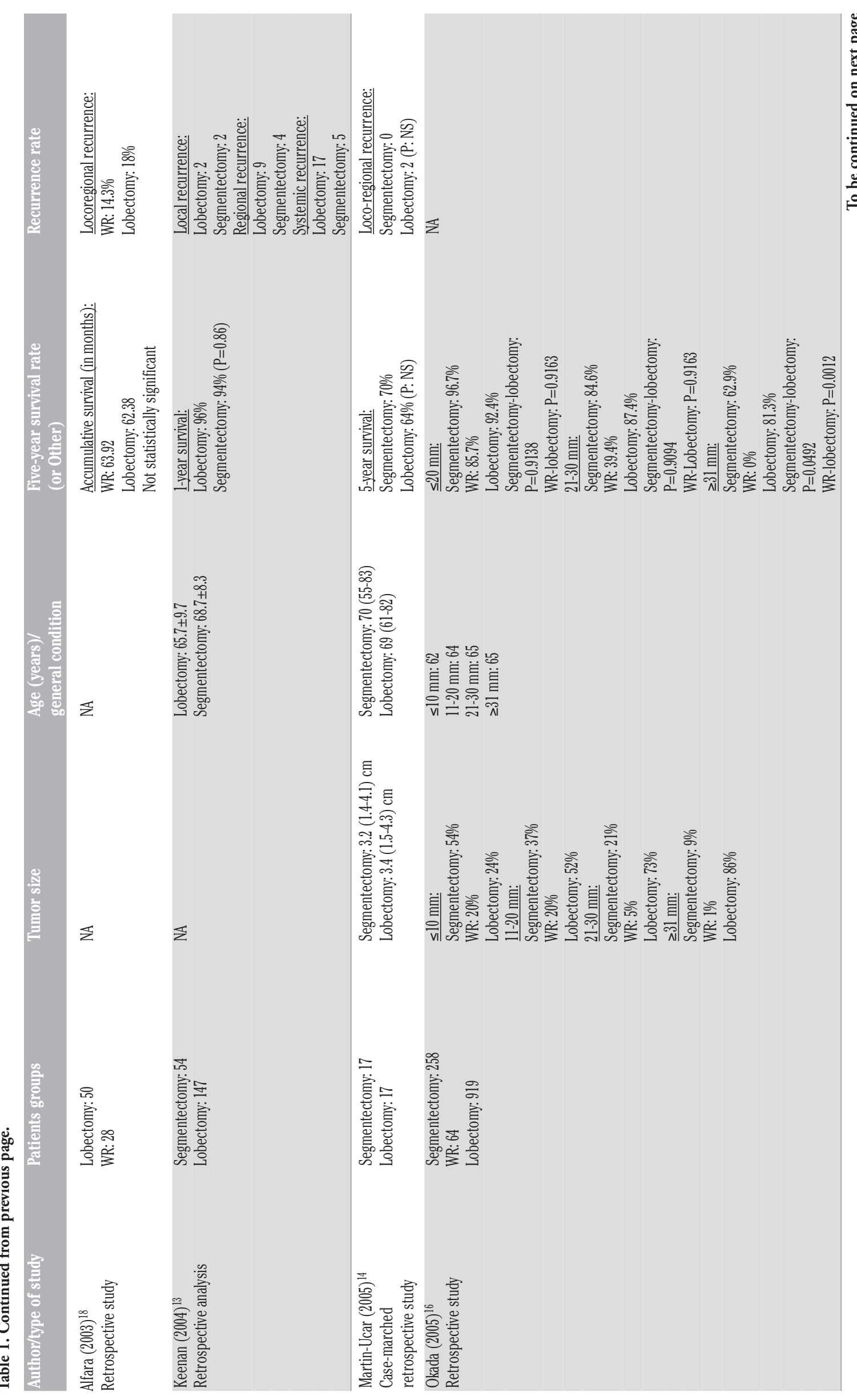




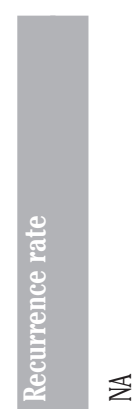

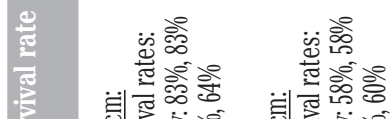

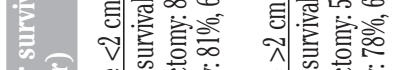

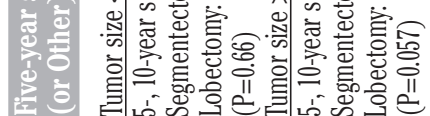

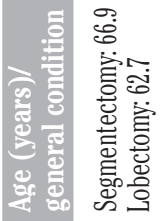
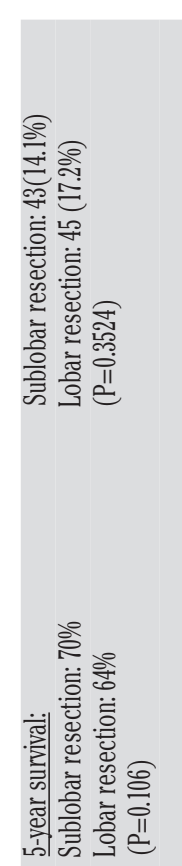
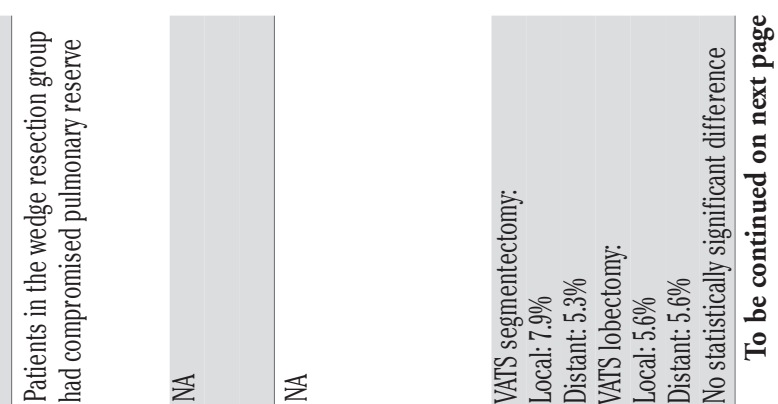

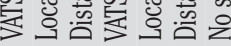

\section{兽

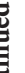

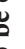

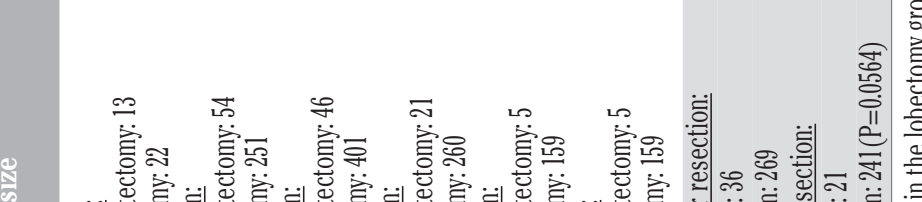

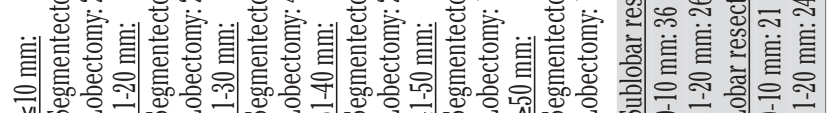
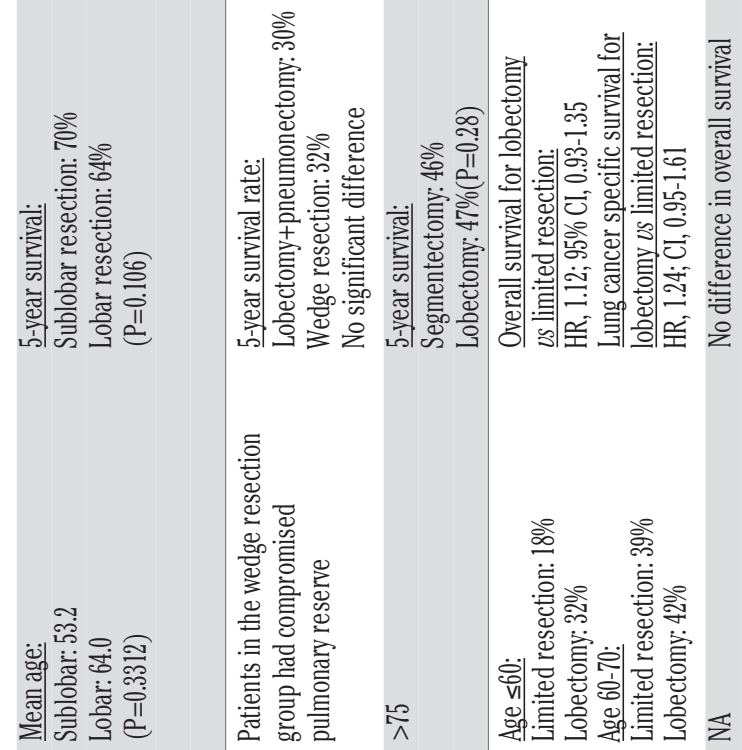

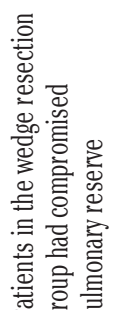

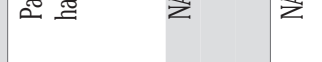

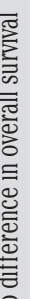

$z$ 

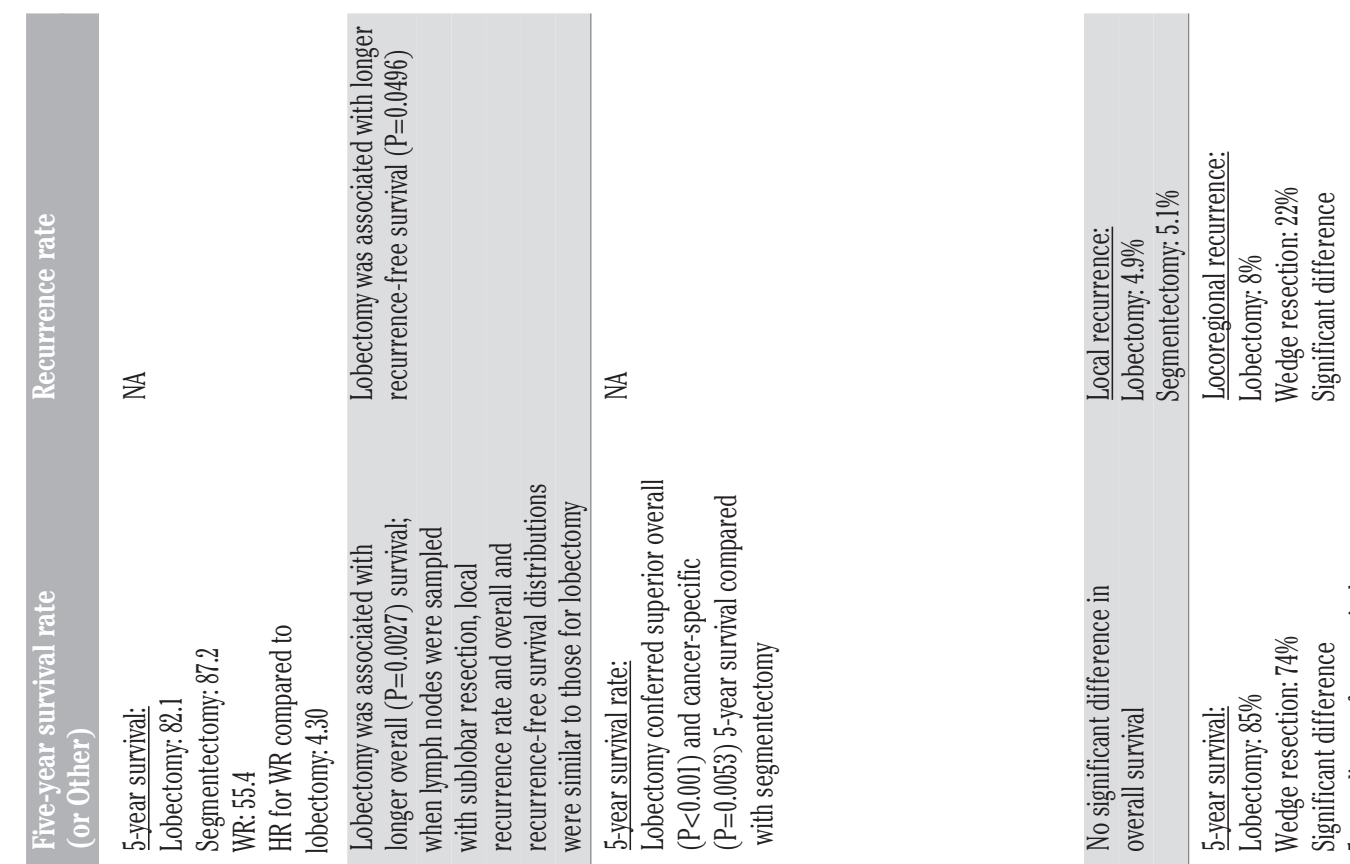

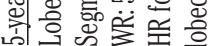

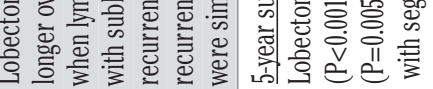
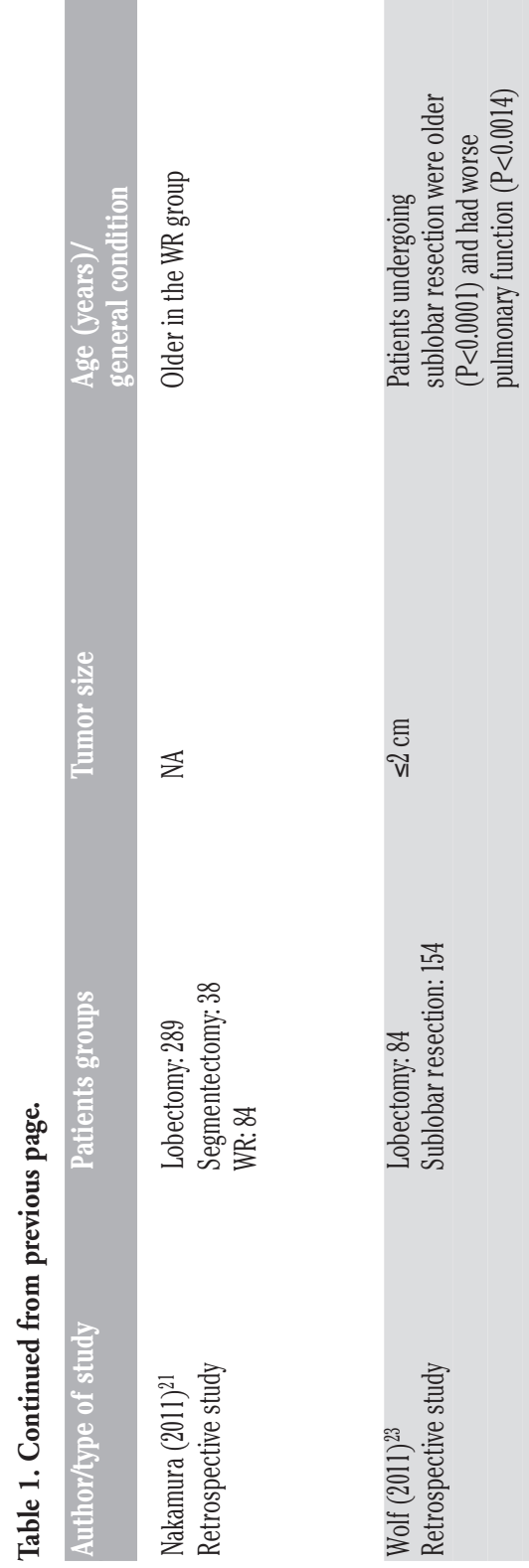

$\underset{\mathrm{V}}{\mathrm{V}}$
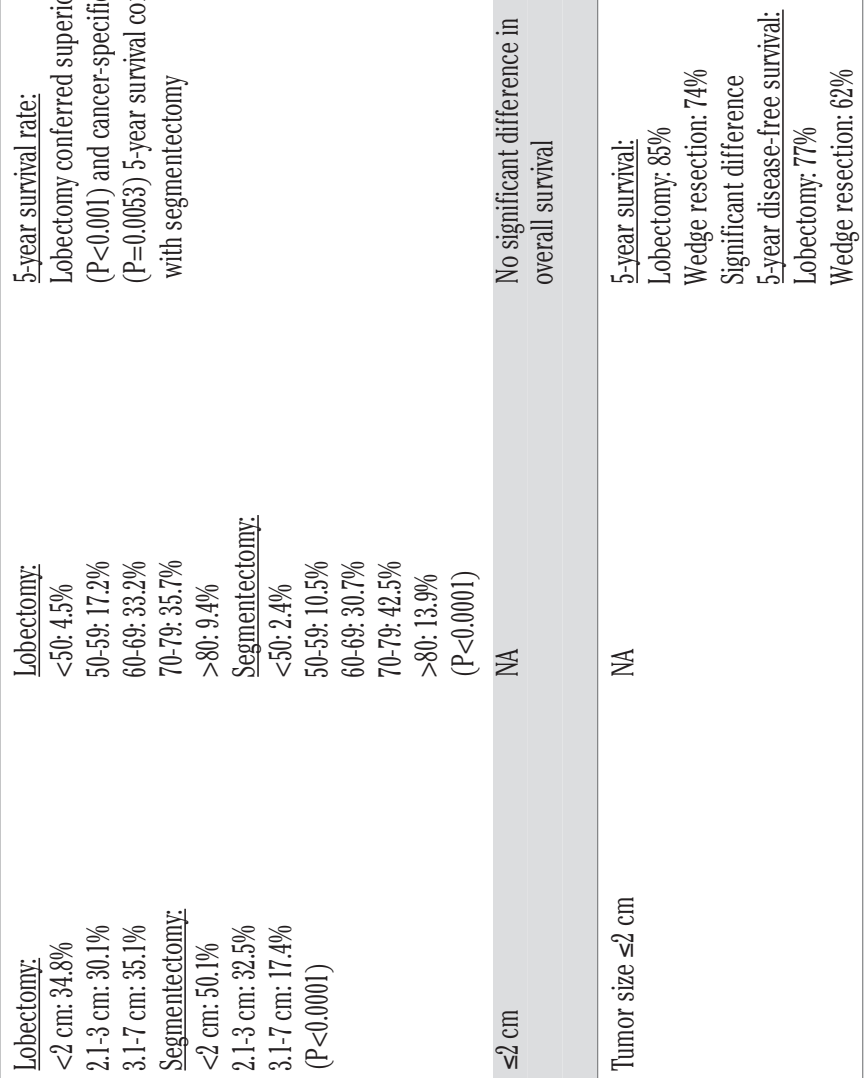


\section{References}

1. Howington JA, Blum MG, Chang AC, et al. Treatment of stage I and II non-small cell lung cancer: diagnosis and management of lung cancer, 3rd ed: American College of Chest Physicians evidencebased clinical practice guidelines. Chest 2013;143:e278S-313S.

2. Ginsberg RJ, Rubinstein LV. Randomized trial of lobectomy versus limited resection for T1 N0 non-small cell lung cancer. Ann Thorac Surg 1995;60:615-23.

3. Yoshikawa K, MD, Tsubota N, Kodama K, et al. Prospective study of extended segmentectomy for small lung tumors: the final report. Ann Thorac Surg 2002;73:1055-9.

4. Tsubota N, Ayabe K, Osamu D, et al. Ongoing prospective study of segmentectomy for small lung tumors. Ann Thorac Surg 1998;66:1787-90.

5. Okumura M, Goto M, Ideguchi K, et al. Factors associated with outcome of segmentectomy for non-small cell lung cancer: long-term follow-up study at a single institution in Japan. Lung Cancer 2007;58:231-7.

6. Miller DL, Rowland CM, Deschamps C, et al. Surgical treatment of non-small cell lung cancer $1 \mathrm{~cm}$ or less in diameter. Ann Thorac Surg 2002;73:1545-51.

7. Errett LE, Wilson J, Chiu RC-J, et al. Wedge resection as an alternative procedure for peripheral bronchogenic carcinomas in poorrisk patients. J Thorac Cardiovasc Surg 1985;90:656-61.

8. Warren WH, Faber LP. Segmentectomy vs. lobectomy in patients with stage I pulmonary carcinoma: five-year survival and patterns of intrathoracic recurrence. J Thorac Cardiovasc Surg 1994;107:1087-94.

9. Landreneau R, Sugarbaker D, Mack M, et al. Wedge resection versus lobectomy for stage I (T1 N0 M0) non-small cell lung cancer. J Thorac Cardiovasc Surg 1997;113:691-700.

10. Kodama K, Doi 0, Higashiyama M, et al. Intentional limited resection for selected patients with T1N0M0 non-small cell lung cancer: a single-institution study. J Thorac Cardiovasc Surg 1997;114:347-53.

11. Okada M, Yoshikawa K, Hatta Takeshi, et al. Is segmentectomy with lymph node assessment an alternative to lobectomy for nonsmall cell lung cancer of $2 \mathrm{~cm}$ or smaller? Ann Thorac Surg 2001;71:956-61.

12. Koike T, Yamato Y, Yoshiya K, et al. Intentional limited pulmonary resection for peripheral T1N0M0 small-sized lung cancer. J Thorac Cardiovasc Surg 2003;125:924-8.

13. Keenan R J., Landreneau R J., Maley R H, et al. Segmental resection spares pulmonary function in patients with stage I lung cancer. Ann Thorac Surg 2004;78:228-33.

14. Martin-Ucar AE, Nakas A, Pilling JE, et al. A case-matched study of anatomical segmentectomy versus lobectomy for stage I lung cancer in high-risk patients. Eur J Cardiothorac Surg 2005;27:675-9.

15. Okada M, Koike T, Higashiyama M, et al. Radical sublobar resection for small-sized non-small cell lung cancer: a multicenter study. J Thorac Cardiovasc Surg 2006;132:769-75.

16. Okada M, Nishio W, Sakamoto T, et al. Effect of tumor size on prognosis in patients with non-small cell lung cancer: the role of segmentectomy as a type of lesser resection. J Thorac Cardiovasc Surg 2005; 129:87-93.

17. Kates M, Swanson S, Wisnivesky JP. Survival following lobectomy and limited resection for the treatment of stage I non-small cell lung cancer $<1 \mathrm{~cm}$ in size: a review of SEER. Chest 2011;139:491-6.

18. Fibla Alfara JJ, Gomez Sebastian G, Farina Rios C, et al. Lobectomy versus limited resection to treat non-small cell lung cancer in stage
I: a study of 78 cases. Arch Bronchoneumol 2003;39:217-20.

19. Kilic A, Schuchert MJ, Pettiford BL, et al. Anatomic segmentectomy for stage I non-small cell lung cancer in the elderly. Ann Thorac Surg 2009;87:1662-6; discussion 1667-8.

20. Yamashita S, Chujo M, Kawano Y, et al. Clinical impact of segmentectomy compared with lobectomy under complete video-assisted thoracic surgery in the treatment of stage I non-small cell lung cancer. J Surg Res 2011;166:46-51.

21. Nakamura H, Taniguchi Y, Miwa K, et al. Comparison of the surgical outcomes of thoracoscopic lobectomy, segmentectomy and wedge resection for clinical stage I non-small cell lung cancer. Thorac Cardiovasc Surg 2011;59:137-41.

22. Zhong C, Fang W, Mao T, et al. Comparison of thoracoscopic segmentectomy and thoracoscopic lobectomy for small-sized stage IA lung cancer. Ann Thorac Surg 2012;94:362-7.

23. Wolf AS, Richards WG, Jaklitsch NT, et al. Lobectomy versus sublobar resection for small ( $2 \mathrm{~cm}$ or less) non-small cell lung cancers. Ann Thorac Surg 2011;92:1819-23.

24. Whitson BA, Groth SS, Andrade RS, et al. Survival after lobectomy versus segmentectomy for stage I non-small cell lung cancer: a population-based analysis. Ann Thorac Surg 2011;92:1943-50.

25. Griffin JP, Eastridge CE, Tolley EA, Pate JW. Wedge resection for non-small cell lung cancer in patients with pulmonary insufficiency: prospective ten-year survival. J Thorac Oncol 2006;1:960-4.

26. Stefani A, Nesci J, Casali C, Morandi U. Wedge resection versus lobectomy for T1N0 non-small cell lung cancer. Minerva Chir 2012;67:489-98.

27. Pastorino U, Valente M, Bedini V, et al. Limited resection for Stage I lung cancer. Eur J Surg Oncol 1991;17:42-6.

28. Churchill ED, Belsey R. Segmental pneumonectomy in bronchiectasis. Ann Surg 1939;109:481-99.

29. Jensik RJ, Faber LP, Kittle CF. Segmental resection for bronchogenic carcinoma. Ann Thorac Surg 1996;62:348-51.

30. El-Sherif A, Gooding WE, Santos R, et al. Outcomes of sublobar resection versus lobectomy for stage I non-small cell lung cancer: a 13-year analysis. Ann Thorac Surg 2006;82:408-16.

31. Harada H, Okada M, Sakamoto T, et al. Functional advantage after radical segmentectomy versus lobectomy for lung cancer. Ann Thorac Surg 2005;80:2041-5.

32. Korst RJ, Ginsberg RJ, Ailawadi M, et al. Lobectomy improves ventilatory function in selected patients with severe COPD. Ann Thorac Surg 1998;66:898-902.

33. Santos R, Colonia A, Pardel D, et al. Comparison between sublobar resection and 125 iodine brachytherapy after sublobar resection in high-risk patients with stage I non-small cell lung cancer. Surgery 2003;134:691-7.

34. Fernando HC, Santos RS, Benfield JR, et al. Lobar and sublobar resection with and without brachytherapy for small stage IA. J Thorac Cardiovasc Surg 2005;129:261-7.

35. Lee W, Daly BD, DiPertill TA, et al. Limited resection for non-small cell lung cancer: observed local control with implantation of I-125 brachytherapy seeds. Ann Thorac Surg 2003;75:237-43.

36. Birdas TJ, Koehler RP, Colonias A, et al. Sublobar resection with brachytherapy versus lobectomy for stage Ib non-small cell lung cancer. Ann Thorac Surg 2006;81:434-8.

37. Koike T, Togashi K, Shirato T, et al. Limited resection for noninvasive broncioloalveolar carcinoma diagnosed by intraorerative pathologic examination. Ann Thorac Surg 2009;88:1106-11.

38. Yamato Y, Tsuchida M, Watanabe T, et al. Early results of a prospective study of limited resection for bronchioloalveolar adenocarcinoma of the lung. Ann Thorac Surg 2012;71:971-4. 